\title{
Sustainable tourism in mountainous regions
}

\author{
K. Meyer-Cech \& U. Pröbstl \\ Department of Spatial, Landscape and Infrastructure Sciences, \\ University of Natural Resources and Applied Life Sciences, Vienna, \\ Austria
}

\begin{abstract}
Trends of tourism in mountainous regions with their manifold economic, social and ecological impacts are dealt with in this paper using the Austrian Alps as an example, and evaluating ways to manage tourist activities and adapt to man-made and natural challenges in accordance with the concept of sustainable development. The first section of this paper deals with the differences in research on tourism trends in Europe and North America concerning approaches and methods used. Trends in Alpine tourism are discussed, such as developments of spatial concentration, socio-demographic changes and new developments in winter tourism. Then possible responses to these trends that will help contribute to a sustainable development of tourist activities in the Alps are illustrated, including regulations relating to spatial planning or nature conservation as well as the management of tourist destinations. Ways of enhancing tourist activities in economically weak areas are touched upon.

Keywords: sustainable tourism, mountainous regions, tourism trends, Austria, Alps, spatial planning, nature conservation.
\end{abstract}

\section{Introduction}

Tourism plays an important role in Austria. The Alps cover two thirds of the country and account for about $85 \%$ of the 118 Mio. overnight stays per year. Only a fraction of the Alpine area, namely less than $15 \%$, can potentially be used for agricultural, settlement and tourist purposes. This narrow space fulfils multiple, often overlapping functions of ecology, living, economy and recreation, a great challenge for spatial planning. The Alps as well as other mountainous regions often are areas of great scenic beauty and high ecological value. At the same time they are habitat for humans and sites of economic production. Aside 
from agriculture tourism is an economic pillar commonly found in mountainous regions. This paper deals with the manifold impacts of tourist activity as well as the manifestations and trends of tourism in mountainous regions, using the Austrian Alps as an example. It exemplifies and evaluates ways to manage tourist activities and how to adapt to man-made and natural challenges in accordance with the concept of sustainable development.

\subsection{Tourism in the Austrian Alps}

Unlike Alpine tourism resorts in France and Italy, tourism in the Austrian Alps also in the Bavarian and South-Tyrolian Alps - is characterised by very small to medium sized enterprises with a high rate of family-run accommodation facilities, second homes included. Tourism development is mostly endogenous and the rate of domestic capital is high. At the same time the indebtedness of Austrian tourism businesses is extremely high. With only few exceptions (e.g. Saalbach-Hinterglemm, Sölden, Mittelberg) even the larger tourism resorts have less than 10,000 tourist beds, a low rate compared to the rest of the Alps [1, p.152].

Looking at the settlement structure one has to differentiate between on the one hand tourism communities that have evolved from agricultural settlements in higher altitudes, usually quite small communities with 1,000 to 3,000 inhabitants. On the other hand there are also urban agglomerations in the Alpine valleys and basins in lower altitudes, such as the provincial capitals Innsbruck and Salzburg, that are surrounded by municipalities with a high commuter rate and more than 5,000 inhabitants (see [2]).

With $48 \%$ in winter versus $52 \%$ in summer [3] the distribution of tourist nights among the seasons is quite even. The total amount of tourist nights is increasing, but due to the growing popularity and affordability of summer holidays at the seaside and other exotic and far off destinations the share of tourist nights in summer has been and still is constantly decreasing. Throughout the year more than $50 \%$ of all tourist nights take place in the two provinces of Tyrol and Salzburg. In winter it is also Tyrol (43\% of overnight stays, 2002/2003) and Salzburg (22\%) who have the greatest share, in summer it is Tyrol $(29 \%$ of overnight stays, 2003) and Carinthia (17\%).

\section{Method and structure of the article}

Based on a literature review the first section of this paper deals with the differences in research on tourism trends in Europe and North America concerning approaches and methods used. In the following section European research on tourism trends is exemplified by discussing selected trends in Alpine tourism, such as developments of spatial concentration, socio-demographic changes and new developments in winter tourism. Then possible responses to these trends that will help contribute to a sustainable development of tourist activities in the Alps are dealt with, including regulations relating to spatial planning or nature conservation as well as the management of tourist destinations. 


\section{Research on tourism trends}

\subsection{Definition}

According to the relevant literature it becomes apparent quickly that trend research in North America and in Europe differs significantly. An emphasis of trend research in North America is to recognise "where we are today in relation to some of yesterday's events. In other words, where are we now and how did we get there" [4, p.1]. Analyses based on these types of questions provide the background for conclusions about future patterns of development. The fundamental differences to trend research in Europe are explained by the same authors: "Trends are based on documented historical precedents. Predictions are based on anything, including the alignment of Jupiter's moons!" [4, p.1]. As recreation researchers, these authors reiterate that their observations are especially applicable to the voluntary human activities of leisure, outdoor recreation, and tourism.

Particularly in Germany and Austria, the term trend itself, as well as trendrelated research is perceived very differently. Here research defines "trends" as contemporary developments, based on and reflecting certain societal conditions and developments. Trends emerge in a condensation of loose themes which eventually bundle and consolidate in new directions of human behaviour. Trend related research describes itself as a combination of social sciences and humanities such as communications, sociology, psychology, and opinion research. For the tourism branch in Europe, which is still focused on the evaluation of statistical data, it is getting obvious that the emergence of trends cannot only be predicted on hand of specific, measurable data, because trends are determined by certain qualities rather than quantities, and a certain amount of uncertainty is inherent to the emergence of new trends. Actual trend research is focused on many societal aspects, including, but not exclusive to, commerce and consumer research, but also integrates recreation, sport and leisure.

Sometimes trends manifest themselves with creative names, such as the retrotopia-trend (the desire for products from the past) and family-fever (the rekindling of stable values, as in the patch-work family), generate publicity in the media [5] and are used for new products and marketing purposes also in tourism. Societal trends such as an increasing emphasis on individuality, and self-determination influence career decisions as well as recreation and leisure participation. An ever increasing number of recreationists prefer to participate in individualistic and casual types of activities rather than as members of a team or club, even if these activities, and particularly their individual pursuit, are associated with higher expenses.

Critics, such as Bursinski [6] and Schwier [7] advise against taking proclaimed trends too literally. In particular they emphasise the lack of transparency of most methods used by trend researchers, and point to the sophisticated marketing associated with trends and trend research, which can only be validated in retrospective. Bolz [8, p.21f] describes the current development in Germany as "trends" that "replace tradition", and that instead of "relying on experience, one carefully explores new trends". 
Studies from Australia however agree that for reviewing national trends both research directions should be considered. Tourism planning and management framework should therefore include a general review of trends in society and how they affect tourism and leisure participation $[9$, p.1,4].

How long trends last is also open for debate. Mega-trends seem to last between 10 and 20 years [10]. Other authors observe ever shorter periods of trends, which nowadays may only last for about five years [11].

\subsection{General societal trends}

Among the general trends, there is the widely recognised demographic change, such as an increase of the older generation. This older generation is more mobile than before, has plenty of disposable income for leisure, recreation, and tourism and considers preventative medical care, such as visits to spas, as an important component of their life. Society is also characterised by an increasing number of new partnerships and changing family structures, which affect the supply of recreation facilities. For example, recreational suppliers specifically target single parent households with youth camps and special group offers.

A counter reaction to the consequences of globalisation is retreating into one's own private sphere, the home, and increasingly to invest in the private idyll of home and garden (so called "cocooning"). In the context of leisure and tourism the concepts of regional context and authenticity, as well as environmentally sound planning of the community and quality of the home are valued more.

The overall societal trend towards an information and knowledge society also affects the domain of leisure and tourism. More and more professional groups are no longer tied to a particular physical setting, but actually may locate based on personal preferences. New communications media enable the emergence of alternative life- and work styles. The concept of a strict five day work week is gradually changing to a more flexible system. This offers the possibility to use this free time for several short trips of three or four days. The new life- and work styles permit more and more recreationists to avoid crowding and congestions during the weekend by pursuing their favourite leisure activities on other days of the week. Another characteristic of the knowledge society is increased mobility with regards to work as well as travel and leisure pursuits. Consequently, demands on tourism offers and their quality also change. The consensus about societal values is diminishing continuously, leading to a plurality of values and increased emphasis on personal values.

In the following chapter we will show the consequences of these societal trends for tourism in the Alps.

\section{Tourism trends in the Austrian Alps}

\subsection{Demographic changes in the host destinations}

The future population development in the Austrian Alps will continuously lead to winning and loosing regions, roughly corresponding to urban or urbanising 
regions on the one hand and mostly peripheral economically weak rural areas on the other. The figures in this chapter are taken from a report published by the Austrian Conference on Spatial Planning on the population trends for Austria's 35 NUTS 3-regions and 118 districts for the next three decades, namely 2001 to 2031 [12]. During this time span population will increase considerably in Alpine cities (e.g. Innsbruck $+11 \%$ ) and their suburban outskirts due to interregional migration. Population growth is also expected along important arterial roads. Peripheral Alpine districts will lose population, e.g. in Carinthia and East-Tyrol. These areas are too far away for commuting and less attractive to reactivate new labour markets. Tourism represents the only counter movement, but often enough cannot stop the trend.

Impacts of this development on tourism in the urbanised and urbanising areas are high pressure on building land and also on politicians to make further land available for tourist, other economic and residential development, resulting in high (often not affordable for local inhabitants) prices for real estate. Aside from the consumption of land and other resources also traffic with all its ecological and social effects is increasing constantly.

Aside from the structural difficulties of tourism in these areas a vital role of tourism is being severely weakened, namely providing and maintaining decentral job opportunities in mountainous areas.

\subsection{Concentration of tourist activities}

Tourist activities are spatially and seasonally concentrated. Small tourism communities with a small offer of tourism infrastructure are continuously forced from the market due to increasing competition. The development towards larger tourist units is clearly visible in Alpine winter tourism. In order to be able to further compete on the international tourist market more and more skiing resorts closely co-operate or even merge. A recent example is the skiing region of Kitzbühel in Tyrol, where more than 30 communities with 241 skiing lifts, that cover 676 kilometres of slopes, and 172 mountain restaurants have joined forces. At the same time smaller skiing lifts and those in lower altitudes close down. According to Bieger [13] in Europe about 80 larger skiing resorts will be able to survive on the international market, 70 of which in the Alps, leaving the remaining 230 to serve smaller markets or to quit altogether.

The impacts of the concentration processes of tourism development are an increasing settlement development and sprawl making the areas that can potentially be used for settlement even more sparse and causing adverse impacts on the ecosystem that can be very sensitive especially in high altitudes. Communities with a tourism mono-structure may use three to five times the acreage for development of a non-tourism community with the same amount of inhabitants. This development is followed by traffic with its emissions, which are often "trapped" in the basins and valleys due to the Alpine relief and the common weather condition of inversion in winter.

Socio-cultural problems of the concentration and growth in Alpine tourism for example can be found in local politics, where the decision making process is more and more dominated by influential tourist stakeholders such as owners of 
hotels or mountain railways. Another example is the increased confrontation of the host communities with expressions of society different from their own leading to a rapid change of values and even loss of orientation (see [1, 14]).

\subsection{Winter sports}

Aside from societal trends global warming has effects on tourism in Alpine areas. Recent studies on the effects of global warming on winter sports destinations expect that only those located above $1,200 \mathrm{~m}$ will be able to ensure acceptable winter sport conditions in the future. According to a recent inquiry half of the tourists will not come anymore, if the conditions continuously worsen or will switch to locations in higher regions. One third will still come but, depending on the snow conditions, probably for short trips only [15].

This confronts the tourism branch with the tendency that the booking of winter sports destinations happens very late and only when good winter sports conditions prevail - with the exception high altitude destinations or those offering glacier skiing, whose booking rates are stable. Furthermore costly Alpine winter sports destinations face an increasing competition with winter sports offers in North America on the one hand and cheep offers of sunshine and beach holidays in the southern parts of the world on the other.

For a while artificial snow making was seen as a solution to the problem by trying to guarantee snow throughout the winter season, yet several reasons speak against this: (i) Global warming keeps reducing the times when optimal, namely cold enough, conditions for producing artificial snow prevail. (ii) Increasing costs every year for artificial snow making due to global warming let cable car enterprises - it is mostly them who offer and manage winter sport facilities search for new concepts to cover the growing expenses, i.e. by asking large hotels to help cover the costs. In average artificial snow can be generated on about $40 \%$ of all ski slopes in Austria, in the main destinations for winter sports this ratio lies at $80 \%$ and more. (iii) Ecological effects of artificial snow on vegetation, soil and wildlife is small in lower altitudes of up to $1,200 \mathrm{~m}$ (see [16]). Using artificial snow in the much more sensitive higher altitudes will increase negative effects, e.g. on the vegetation due to a shorter growing season and soil erosion.

\subsection{Globalisation of the tourist offer}

Tourism destinations in the Austrian Alps evolved from agricultural settlements with a high percentage of family run enterprises. This circumstance resulted in a variety of - even though not always quite professional - very unique tourist offers due to their strong regional embeddedness. Today one can witness a growing gap between (often small scale) tourist offers that require local and regional assets on the one hand such as nature or food based tourism, and on the other hand tourist offers that are created in answer to global trends such as certain trend sports, theme parks or event based tourism. Baumgartner [17] speaks of "farm holidays" versus "fun and action". Popular examples for the latter development are the village of Ischgl with its regular glacier pop concerts 
and other events and the brand park of the renowned crystal company Swarowski, both situated in Tyrol. The development towards tourist offers that need to be less or not at all regionally embedded, corresponds to the trend of individualisation as described by Schulze [18], whereby importance of inward orientation and the experience of the self grows in exchange for outward orientation and the experience of the natural surroundings.

One of the effects of this development is that Alpine destinations, which are becoming more and more interchangeable, are entering a self-made global competition with other tourism destinations on a global level (see e.g. [19]).

\subsection{New target groups}

Demographic change has brought a new target group for tourism: the "generation $50+$ ", which - different than 15 years ago - is more mobile and interested in travelling and has more disposable income than the average population. Austrian tourism enterprises are adapting their offers to the needs and interests of this target group. Under the term "wellness" the Austrian tourism branch developed an expanding offer for maintaining fitness and wellbeing and has reached a leading position compared to other Alpine regions. From 1997 to 2002 the number of specialised "wellness"-hotels in Austria has increased from 88 to 536, i.e. a growing rate of $609 \%$ in 5 years.

Another response to this new target group is complementing offers for hiking and biking in the mountains with location based services and guidance via GPS, thereby providing information on the cultural landscape, local tradition, wildlife and local products. The use of a GPS-guided tour in co-operation with a hotel or tourism centre makes the guests feel safely guided. As recent studies point out though $[16,20]$ the technology and design still have to be further adapted to the needs of the "generation 50+".

\section{Response}

The responses encompass strategies of where and how tourist activity should take place as well as strategies of further enhancing tourism development. One has to differentiate between intensively used tourist areas (and further if they have one or two high seasons) and peripheral areas with small scale tourist activities.

\subsection{Regulating tourist activity}

a) Spatial planning and nature conservation regulations relating to tourism can be found on the international over the provincial down to the community level. The Alpine convention (Alpenkonvention) is an international treaty of the Alpine states on the protection of the Alps. In those countries that have ratified its implementation regulations, as Austria has done, these are part of effective law. In Tyrol a connection of two skiing resorts just outside the province's capital of Innsbruck was denied in March 2004 based on the implementation regulations of 
the Alpine Convention. The establishment of the network of Alpine protected areas in the second half of the 1990ies is another example of a result of the Alpine convention with effects on tourism.

Regulations can also be found on the provincial level (spatial planning as well as nature conservation are not federal but provincial matters in Austria). The Tyrolean nature conservation act provides that so-called "Ruhegebiete" (areas of rest), i.e. areas that shall not be disturbed by any development for skiing or traffic, are installed. More than half a dozen have actually been established already. Two provinces (Tyrol and Salzburg) have enacted guidelines restricting the further designation of skiing lifts and cable cars. The development of new skiing areas is prohibited, the enlargement of existing ones is linked to the fulfilment of certain requirements such as no negative impacts on existing hiking trails, making do with existing accommodation capacities or the accessibility by public transport. Furthermore some provincial planning acts have provided for special dedications in land use plans. On the regional level various concepts exist that are based on the principle of graded intensity of (tourist) use ranging from areas where no human interference is allowed over areas with low infrastructure, nature based tourism to areas of high intensity tourism. Examples are the implementation of national parks, biosphere reserves and regional planning programs.

b) The management of tourist destinations is another way of regulating tourist activity. On the local level communities set limits to tourist development, e.g. limits to tourist beds per enterprise or municipality or limits for the number of day passes that are allowed to be sold per day. Some ban automobile traffic from the village core or look for comprehensive solutions to incoming as well as traffic within the destination. Another response is improving the quality of the tourist offer, which means less but higher quality tourist amenities in favour of less tourists and yet at the same time higher value added per unit of supply. The successful initiative "farm holidays" exemplifies how a professional quality management support by a national umbrella organisation contributes to an increase in the market share of its member farms even in times of decreasing overnight stays in the segment of privately run accommodation facilities.

In very sensitive, protected areas, like Natura 2000 sites, a management plan integrates ecological, social and economic interests. A solid database about ecological, local social, and visitor information, as well as analytical tools that integrate these data effectively into the planning process are required. Furthermore, the management plan should enhance a participatory planning process to ensure significant contributions to reach sustainability in tourism regions. Options of public involvement and collaborative planning may include public information sessions, followed by working groups guided by local and external experts, and field work to determine specific management measures.

\section{2 (Re-)Embedding tourism development in the region}

The strategy of regionally embedding tourist activity applies for destinations with intensive tourism as well as for areas where tourism is viewed as a means of sustainable community or regional development. It aims at linking tourist 
development to local or regional assets such as farm produce or cultural heritage, making use of existing resources in terms of accommodation, services, traditions and skills as well as creating regional networks of tourist and non-tourist stakeholders. Agriculture plays a particularly important role in this strategy, several examples of partnerships between tourism and agriculture can be found in Alpine tourism. They range from direct sale of farm products to tourists, over offering services - such as guided tours or seminars - and accommodation and/or meals, to opportunities of part-time employment for farmers, especially also for farm women, in the tourism industry. Only very few examples exist in Alpine tourism for paying off farmers for the provision of a vital resource in tourism, i.e. the scenic beauty of the cultural landscape (e.g. the municipalities of St. Anton am Arlberg in Tyrol or Weissensee in Carinthia) or for the provision of Alpine pastures for skiing slopes and lifts (e.g. respective compensation payments of agrarian co-operatives in Carinthia). The farmers are paid according to the amount of cultivated area or cattle units with revenues derived from the visitors' tax or coming from the municipality, cable car companies or the tourist board. In the case of compensation payments for skiing lifts the turnover of the lift company and the length of cables crossing the Alpine pasture are further criteria.

\section{Conclusions and recommendations}

This paper showed how combining measurable data and societal trends can give insight into emerging new trends relevant for mountain tourism: e.g. demographic and technological changes, spatial concentration processes of residential and tourist activity, global warming or the globalisation of the tourist offer with at the same time its counter trend of regionalisation.

The majority of the impacts of the discussed trends in Alpine tourism can be summarised under three headings: (i) effects of over use, (ii) structural problems and (iii) loss of functions that lie beyond business economics. Over use means consumption of scarce land and other resources as well as the invasion and impairment of sensitive high altitude ecosystems due to recreational use, settlement and tourist development and traffic. Structural problems are mostly related to the character of the tourist offer, i.e. a lack of professionalism and quality amenities, one-sided attention on fair weather tourism in summer and skiing related tourism in winter as well as strong time and space related concentration of overnight stays. Examples for the loss of functions of tourism in mountainous areas that lie beyond business economics can be found in the ecological realm, e.g. the change of Alpine landscapes, as well as the economic and socio-cultural realm, e.g. a loss of provision of jobs and therefore a declining population density in peripheral mountainous areas.

The last paragraph states how the responses exemplified in this paper follow the principles of sustainable tourism and it contains complementary recommendations. (i) Creating new, creative and innovative tourist offers, e.g. making use of new communication media, and responding to new target groups such as the $50+$ generation, is necessary for economic viability. (ii) Regulating tourist activity through spatial planning and nature conservation measures 
contributes to the wise use of resources, the wellbeing of the host population and to keeping local culture intact. The potential of the legal framework needs to be further realised in this matter and complemented with voluntary measures on all territorial levels. (iii) (Re-)embedding tourist activities in the region complies with the principles of establishing short way supplies and fostering regional identity. Regionally embedded co-operative arrangements need to be established: firstly, they help overcome the fragmentation of the tourist offer. Secondly, transaction costs for marketing can be lowered. Thirdly, by helping to position and brand a region and creating a feeling of togetherness among its inhabitants, involving local/regional stakeholders is essential for establishing a strong regional corporate identity and communicating a clear image of the tourist destination to potential guests. The ownership structure in Alpine tourism, where small and medium sized enterprises dominate, represents a challenge for cooperations on the one hand, but can be viewed as a definite advantage in terms of creating an authentic tourist product. And as a fourth point, establishing regional networks might reduce the one-sided dependency of some destinations on skiing lifts and snow by helping to diversify the tourist product.

Recreation and tourism have a high economic importance, at the same time the Alps encompass a great array of ecologically sensitive habitats, which means that a balance between regulation and development policy needs to be found. Yet often the great variety of Alpine tourism is not taken into consideration enough: different tourism structures call for very different and especially regionally specific strategies of response.

\section{References}

[1] Baetzing, W., Die Alpen - Geschichte und Zukunft einer europaeischen Kulturlandschaft. 2nd ed, Beck Verlag: Muenchen, 2003.

[2] Baetzing, W., Der Stellenwert des Tourismus in den Alpen und seine Bedeutung für eine nachhaltige Entwicklung des Alpenraums. Der Alpentourismus - Entwicklungspotenziale im Spannungsfeld von Kultur, Ökonomie und Ökologie, ed. K. Luger and F. Rest. Studienverlag: Innsbruck, p. 175-196, 2002.

[3] Statistik Austria, Tourismus in Österreich 2003: Wien, 2004.

[4] Gartner, W.C., Lime, D.W. Trends in Outdoor, Recreation, Leisure and Tourism, CABI Publishing: Wallinggfort, Cambridge, 2000.

[5] Horx, M. and Wenzel, E., Trend Report 2004, Wien, 2004.

[6] Bursinski, M., Trends und Erfolgsfaktoren in der Freizeit-, Tourismusund Kulturbranche. MSP-Newsletter 5 (12 May 2003): p. 8-9, 2003.

[7] Schwier, J., "Do the right things" - Trends im Feld des Sportes, $d v s-$ Informationen 13, p. 7-13, 1998.

[8] Bolz, N., cited after A. Steinle and P. Wippermann ed.: Trend 2004: Arbeit - Freizeit - Eigenzeit München, 2003.

[9] Gray, P., 2001, Trends in Sport and Recreation, in: http://www.development.tas.gov.au/sportrec/publications/cradlecoast/tren ds.pdf. 
[10] Horx, M. and Wippermann, P., Was ist Trendforschung, Econ Verlag: Berlin, 1993.

[11] Rupe, C., Trends im Abenteuersport: Touristische Vermarktung von Abenteuerlust und Risikofreude. Tourismus - Beiträge zu Wissenschaft und Praxis. Vol. 1: Hamburg, 2000.

[12] OEROK - Oesterreichische Raumordnungskonferenz, OEROK-Prognosen 2001-2003: Teil 1: Bevoelkerung und Arbeitskraefte nach Regionen und Bezirken Oesterreichs. Schriftenreihe Nr. 166/I. Vol. 1: Wien, 2004.

[13] Bieger, T. u. M., Perspektiven der Schweizer Bergbahnbranche. Analyse, drei Szenarien und Moeglichkeiten fuer neue Konfigurationen St. Gallen, 2000.

[14] Bachleitner, R. and Penz, O., Massentourismus und sozialer Wandel Tourismuseffekte und Tourismusfolgen in Alpenregionen. Tourismuswissenschaftliche Manuskripte. Vol. 10, Profil: Salzburg/Wien, 2000.

[15] Baumgartner, P., Fehr, R., and Lötscher, H., Klimaänderung in Graubünden. 2002, Amt für Klimaänderung Graubünden,: Chur. p. 28.

[16] Lampl, R. and Pröbstl, U., GPS-Nutzungen in der Freizeit - neue Entwicklungen und Optionen. Angewandte Geoinformatik 2006. Beiträge zum 18. AGIT-Symposium Salzburg ed. J. Strobl, T. Blaschke and G. Griesebner, Wichmann Verlag: Heidelberg, in press, 2006.

[17] Baumgartner, C., Best Practise Modelle in den Alpen - Von Abkürzungen, Irrwegen und Labyrinthen. Der Alpentourismus - Entwicklungspotenziale im Spannungsfeld von Kultur, Ökonomie und Ökologie, ed. K. Luger and F. Rest. StudienVerlag: Innsbruck, p. 321-336, 2002.

[18] Schulze, G., Die Erlebnisgesellschaft. Kultursoziologie der Gegenwart. 8th ed, Campus Verlag: Frankfurt a. Main, 2000.

[19] Wöhler, K., Die alten Alpen? Nachhaltigkeit und bewahrender Fortschritt. Der Alpentourismus, ed. K. Luger and F. Rest. Studienverlag: Innsbruck, p. 269-280., 2002.

[20] Brandner, C., Optimierung der Benutzerfreundlichkeit eines GPS und LSB basierten digitalen Wanderführers unter Berücksichtigung der Generation 50 plus. BOKU Wien: Vienna, 2006. 